\title{
ARTE VISUAL CONTEMPORÂNEA, ILUSTRAÇÃO E LITERATURA PARA A INFÂNCIA: FAZENDO CONEXÕES ENTRE MUNDOS CRIATIVOS
}

Leonardo Charréu ${ }^{1}$

\section{Resumo}

O texto que se segue parte de duas premissas básicas normalmente aceitas pela comunidade cientifica que estuda, no vasto campo das ciências da educação, aquele que diz respeito à educação infantil. A primeira premissa é a de que uma literatura para a infância de qualidade, experienciada e proporcionada logo no início de qualquer processo, ou ciclo educativo, é de crucial importância para a formação e atração para a leitura por parte de um imaginário futuro leitor, mais a montante, na sua idade adulta. A leitura é efetivamente de fundamental importância para a constituição subjetiva da criança. A segunda premissa parte do princípio que uma imagem visual de qualidade, veiculada pela ilustração infantil, é igualmente importante na ampliação, nos efeitos e nos impactos dos conteúdos da escrita e da "história contada" sobre os(as) seus(suas) pequenos(as) leitor(es)(as). Por fim, uma outra ideia não menos importante, e que será, por assim dizer, a tese defendida neste texto, é a de que a arte visual contemporânea, fenômeno cultural que encerra, sem sombra de dúvida, muita hibridez, diversidade e complexidade, apresenta muitas soluções estéticas que influenciam um número apreciável de ilustradores de livros infantis. De algum modo, o contato visual das crianças com formas visuais que possuem uma dimensão performativa e experimental que é, em parte, transferida das propostas artísticas visuais atuais, também é uma forma paralela de educação estética visual. Assim as crianças não aprendem só a partir do textual, aprendem também a partir do visual, começando a preparar-se para as complexas e vibrantes visualidades com que são confrontados no seu cotidiano.

Palavras Chave: Educação Infantil, Literatura infantil, Ilustração infantil, Arte Visual Contemporânea, Cultura Visual, Criatividade.

\section{Contemporary visual art, illustration and literature for children: Making connections between creative worlds.}

\section{Abstract}

The following text starts from two basic assumptions normally accepted by the scientific community that study, within the vast arena of educational sciences, the field that relates to children's education. The first assumption is the one which states the idea of the significance of quality literature for children, experienced and provided from the very beginning of any educational process or cycle. This is of crucial importance for the formation and attraction in reading by a hypothetical future reader, until their adulthood. Reading, definitely, is of fundamental importance to the subjective constitution of the child. The second premise assumes that quality visual images provided by children's illustrations, is also important to expand on the effect and impact that the content of

\footnotetext{
${ }^{1}$ Leonardo Charréu, é professor no Departamento de Pedagogia e Educação da Universidade de Évora e é investigador no CIEP, Centro de Investigação em Educação e Psicologia, onde coordena a linha de Investigação "Arte, Educação e Comunidade", sendo igualmente membro colaborador no núcleo de Educação Artística no IADS, Instituto de Investigação em Arte, Design e Sociedades da Universidade do Porto. Licenciou-se em Belas Artes - Pintura na Faculdade e Belas Artes do Universidade do Porto, é mestre em História da Arte pela Universidade Nova de Lisboa e Doutor em Belas Artes pela Universidade de Barcelona e em Ciências da Educação pela Universidade de Évora. Tem cerca de cinco dezenas de trabalhos publicados em livros e revistas da especialidade. A componente artística na formação de professores, a cultura visual, os novos ambientes de educação informal e as relações entre arte e ciência, a cognição e a ilustração, são os seus principais interesses de investigação. leonardo@uevora.pt
} 
writing and the "told story" has on these little readers. Finally, another idea, just as important, that will indeed be the main argument of this text, is that contemporary visual art, which is a cultural phenomenon that requires, indubitably, a lot of hybridity, diversity and complexity, has many aesthetic solutions that affect a significant number of children's book illustrators. Somehow, the children's contact with visual forms that have a performative dimension that is experimental and, in part, transferred from the current visual artistic proposals, is also a form of parallel visual aesthetic education. So children do not learn only from the text, they also learn from the visual, starting their preparation for the complex and vibrant visualities they face in their daily lives.

Key Words: Childhood Education, Children's literature, children's illustration, Contemporary Visual Art, Visual Culture, Creativity.

"...Indubitavelmente, se uma imagem pode dar formas às palavras, as palavras podem dar uma voz à imagem silenciosa"

(Adel Gorgy, Fotógrafo, NY)

\section{Introdução}

Muitos projetos, reformas, relatórios e documentos orientadores de politicas educativas de muitos países que hoje se vão dando a conhecer sobre educação, um pouco por todo o mundo, têm colocado uma ênfase muito grande apenas em duas ou três grandes áreas do saber, entre as muitas formas de saber que, conhecemos hoje, interagem as chamadas inteligências múltiplas. São pelo menos sete, identificadas e propostas pelo psicólogo norte-americano Howard Gardner (1983, 1999). Essas três grandes áreas do mundo escolar que têm merecido um grande enfoque politico e um maior interesse social são, indubitavelmente, a Leitura, a Matemática e a Ciência.

O famoso relatório PISA (Programme for International Student Assessment), publicado regularmente pela OCDE desde o ano 2000, procura aferir o nível de conhecimentos nessas três áreas por alunos com 15 anos. Outros testes e relatórios similares existem, como o TIMSS (Trends in International Mathematics and Science Study) que só procuram aferir conhecimentos em Matemática e Ciência excluindo desta vez a leitura. Estes relatórios reproduzindo uma visão de educação muito redutora têm todavia gerado imensos debates políticos sempre que saem a público. Nenhuma nação quer "ficar mal na fotografia", descendo no ranking em relação ao período anterior e quando isso acontece, nos regimes democráticos, a oposição política critica negativamente os governos e respectivas politicas educativas pelos resultados obtidos. 
No entanto, algumas vozes têm recentemente se juntado à dos tradicionais defensores de uma educação mais ampla e mais integrada, contemplando um leque muito mais vasto de inteligências e saberes julgados fundamentais para compreender o século XXI e o enorme conjunto de desafios que ele vai exigir ao cidadão comum.

Se há alguns anos atrás era essencialmente o livro o meio pelo qual os vários autores de distintas áreas, que iam da pedagogia à filosofia, defendiam a importância do ensino artístico (Herbert Read, Viktor Lowenfeld, Nelson Goodman, etc.), actualmente o veículo para muitas destas vozes alternativas é a internet. Um bom exemplo são os vídeos que são de forma crescente colocados no youtube ${ }^{2}$, entre os quais se pode destacar o de Ken Robinson, um perito em educação, que apresenta uma bem-disposta e incisiva comunicação sobre educação, criatividade e a importância do ensino das artes.

No entanto, a obra impressa, em particular a que tem a sorte de poder ser ilustrada, procura ainda resgatar do esquecimento esse objeto tão extraordinário chamado "livro" que muitos arautos e defensores do tecnofetichismo virtual digital têm vindo a condenar, com alguma dose de exagero, ao desaparecimento. Todavia, o livro vai resistindo e nunca como hoje se venderam tantos livros no mundo.

A ilustração infantil, em particular, aquela que consideramos de qualidade, conjuga o potencial persuasivo das imagens com a fluidez da narratividade do texto literário. Deverá ser tão poético quanto sensível pois se trata de texto destinado às crianças. Em certa medida, o livro ilustrado infantil constitui, em casos meritórios que destacaremos, um feliz casamento entre as dimensões visuais e literárias da arte. A natureza do público a que se destinam os livros ilustrados tornam pois a tarefa de escrever e de ilustrar para crianças como uma das mais desafiantes e mais criativas para muitos escritores e artistas visuais contemporâneos. Muitos acabam por se especializar nesta área, abandonando os seus projetos no âmbito da chamada "grande arte", ou seja aquele que circunscreve os campos da arte erudita e crescentemente elitista, para abraçarem desafios editoriais criativos e arrojados. O corolário desta atitude traduz-se numa espécie de tendência para a Editora de livros infantis transmutar-se num tipo de galeria de arte dinâmica, com imagens móveis que viajam nos/com os textos dos livros. E os artistas, pelo menos uma boa parte deles, já perceberam esse potencial.

\footnotetext{
${ }^{2} \mathrm{O}$ vídeo datado de Fevereiro de 2006 pode ser visto nos seguintes endereços, sendo dividido em dois: http://www.youtube.com/watch? $v=y$ Fi1mKnvs2w e em http://www.youtube.com/watch?v=0pn_oTIwy4g\&feature=watch_response
} 


\section{A Arte Visual Contemporânea: Crítica, definições e tendências}

Normalmente os historiadores, os críticos e teóricos da arte contemporânea tendem a enquadrá-la entre o presente e um passado que se costumam situar no século passado, no período pós segunda Guerra Mundial. Deste modo, a data referência é a de 1945, ano em que terminou oficialmente o conflito mundial.

Como característica fundamental do desenvolvimento artístico desde as primeiras décadas do pós-guerra até à contemporaneidade, destaca-se o numero extraordinário de movimentos que desabrocharam em cada década, tendo alguns efetuado a transição de uma para outra. Há décadas com uma média estonteante de mais de um "movimento" ou proposta estética por ano, o que dá uma ideia da vitalidade e da complexidade do fenômeno da arte contemporânea (Cfr. Quadro1).

A Arte Contemporânea e o mainstream que a sustenta tornou-se um dos mais importantes negócios, atingindo hoje um lugar cimeiro entre as chamadas indústrias culturais. E não é por acaso que o sucesso de qualquer uma das grandes bienais de arte (Kassel, São Paulo, Veneza, Madrid etc.), já não se mede só pelo número expresso de visitantes, mas também pelo volume de dinheiro movimentado, ambos com tendência de crescimento.

No entanto, sublinhe-se que na dinâmica criativa que faz emergir constantemente novos movimentos e novos artistas, obedecendo a lógicas de mercado e, consequentemente, a tendências de oferta e de procura, não consegue muita vezes esgotar em tão curto espaço de tempo o potencial criativo que as inspira. Daí que se compreenda a passagem de determinados movimentos de um ano para o outro, às vezes de uma década para outra, por precisamente se encontrarem muitas vezes ativos os pressupostos e as chamadas "tensões vitais" que os inspiraram. Entenda-se por "tensão vital" tudo o que no âmbito civilizacional-cultural tem tal força e tal potencial expressivo que apenas necessita de um(a) artista sensível para a traduzir em forma estético-plástica. Algumas destas tensões, indesmentivelmente possuem configurações sociais, ou incidem sobre grupos que de alguma forma sempre estiveram esquecidos ou em desvantagem.

Daí que o femininismo, o multiculturalismo, a arte transgressiva e a arte transhumana, por exemplo, sejam movimentos que, marcando as décadas em que emergiram, continuam a marcar a obra de muitos artistas atuais, que ora regressam a estes temas por não os considerarem esgotados, ou os redescobrem entre a oferta ainda viva do imenso mostruário de opções sintetizadas no Quadro 1. 
Todos estes movimentos podem, portanto, ser analisados a partir de vários ângulos. Algumas vozes intelectuais que provêm de campos tão vastos que vão da critica de arte à sociologia e desta ao amplo espectro dos estudos culturais consideram, de uma forma mais ou menos depreciativa, muitos destes movimentos como uma resposta mais ou menos atabalhoada a uma pressão evidente de uma sociedade de consumo.

Esta dimensão consumista que caracteriza indelevelmente a sociedade contemporânea, segundo esta perspectiva, acabaria também por permeabilizar o chamado consumo cultural e o objeto artístico que, como qualquer produto sujeito à apreciação ou aquisição humana, poderia eventualmente ser distorcido nos seus propósitos de genuíno objeto consubstanciado e produzido a partir de uma "pulsão vital" inspiradora.

Esta pode ser, como vimos antes, proveniente de vários campos e possui consequentemente um poder de alimentação do trabalho artístico potencialmente infinito porque serão qualitativamente diferentes os problemas que cada época tem de enfrentar. Considera-se, assim, a profusão exponencial de propostas e movimentos artísticos que se desenvolveram desde o pós-guerra como uma resposta e reação natural do mundo da arte face às profundas mudanças que vão ocorrendo no processo civilizacional, levando em linha de conta a velocidade a que ocorrem e a consequente exigência e apetência por novas formas, novas mídias e novas estéticas. Se bem que esta última perspectiva nos pareça ser a que tem mais seguidores, não é menos certo que em determinados momentos uma certa necessidade artificial de criar o novo, ou um pseudo-novo ${ }^{3}$ procura impor-se, o que faz com que muitos artistas acabem por seguir o que é imposto por certas formas de marketing que tendem a tolher e a repetir formas e propostas mais vendáveis e mais fáceis de comercializar. Desta forma, propostas artísticas e movimentos com mais impacto e mais próximas de um fenômeno colateral, como o é o da moda, tendem a transmutar-se noutros movimentos com outras designações mas que no essencial acabam por repetir fórmulas anteriores.

Quadro 1: Movimentos Artísticos Contemporâneos 1950-2010

\begin{tabular}{|l|l|l|}
\hline \multicolumn{1}{|c|}{ 1950s } & \multicolumn{1}{c|}{ 1960s } & \multicolumn{1}{c|}{1970} \\
\hline - Abstract Expressionism & - Abstract expressionism & - Arte Povera \\
- American Figurative & - American Figurative \\
Expressionism & Expressionism & - Ascii Art \\
- Bay Area Figurative & - Bad Painting \\
Movement & - Abstract Imagists & - Body art \\
- Lyrical Abstraction & Bay Area Figurative & - Artist's book \\
Movement & - Feminist art \\
\hline
\end{tabular}

\footnotetext{
${ }^{3}$ A este respeito consultar a obra de Harold Rosenberg "The Tradition of the New (publicada originalmente em 1959 em New York: Horizon Press).
} 


\begin{tabular}{|c|c|c|}
\hline $\begin{array}{l}\text { - New York Figurative } \\
\text { Expressionism } \\
\text { - New York School }\end{array}$ & $\begin{array}{l}\text { - Color field } \\
\text { - Computer art } \\
\text { - Conceptual art } \\
\text { - Fluxus } \\
\text { - Happenings } \\
\text { - Hard-edge painting } \\
\text { - Lyrical Abstraction } \\
\text { - Minimalism } \\
\text { - Neo-Dada } \\
\text { - New York School } \\
\text { - Nouveau Réalisme } \\
\text { - Op Art } \\
\text { - Performance art } \\
\text { - Pop Art } \\
\text { - Postminimalism } \\
\text { - Washington Color School } \\
\text { - Kinetic art }\end{array}$ & $\begin{array}{l}\text { - Installation art } \\
\text { - Land Art } \\
\text { - Lowbrow (art } \\
\quad \text { movement) } \\
\text { - Photorealism } \\
\text { - Postminimalism } \\
\text { - Process Art } \\
\text { - Video art } \\
\text { - Funk art } \\
\text { - Pattern and Decoration }\end{array}$ \\
\hline 1980s & 1990s & 2000s \\
\hline $\begin{array}{l}\text { - Appropriation art } \\
\text { - Culture jamming } \\
\text { - Demoscene } \\
\text { - Electronic art } \\
\text { - Figuration Libre } \\
\text { - Graffiti Art } \\
\text { - Live art } \\
\text { - Mail art } \\
\text { - Postmodern art } \\
\text { - Neo-conceptual art } \\
\text { - Neo-expressionism } \\
\text { - Neo-pop } \\
\text { - Sound art } \\
\text { - Transgressive art } \\
\text { - Transhumanist Art } \\
\text { - Video installation } \\
\text { - Institutional Critique }\end{array}$ & $\begin{array}{l}\text { - Bio art } \\
\text { - Cyberarts } \\
\text { - Cynical Realism } \\
\text { - Digital Art } \\
\text { - Information art } \\
\text { - Internet art } \\
\text { - Massurrealism } \\
\text { - Maximalism } \\
\text { - New Leipzig School } \\
\text { - New media art } \\
\text { - Software art } \\
\text { - New European Painting } \\
\text { - Yung British Artists }\end{array}$ & $\begin{array}{l}\text { - Classical realism } \\
\text { - Relational art } \\
\text { - Street art } \\
\text { - Stuckism } \\
\text { - Superflat } \\
\text { - Videogame art } \\
\text { - Superstroke } \\
\text { - VJ art } \\
\text { - Virtual art } \\
\text { - Imagine \& Poesia }\end{array}$ \\
\hline
\end{tabular}

Nota: Os nomes dos movimentos artísticos foram mantidos no seu original inglês não só para facilitar posterior pesquisa mas também pela razão de se tornar bastante redutor a tradução de designações que pouco diferem da sua designação original em inglês.

Autores como Berleant (1992, 422 e segs.) estudando há quase cerca de vinte anos o que de significativamente afetou e inspirou as práticas artísticas identificadas e ordenadas no quadro anterior, sintetizaram em três grandes mudanças, que se interrelacionam, as razões que levaram a tal explosão de propostas estéticas que marca indelevelmente a arte contemporânea (Cfr. Quadro 2).

Berleant sugere que tal profusão de novos movimentos artísticos, em quantidade e em qualidade, só ocorreu porque apareceram novas tecnologias e novos materiais (plásticos, acrílicos, neóns, etc.) rapidamente apropriados pelos artistas como "materiais de expressão" dando origem à possibilidade de moldar e conceber novos objetos, atribuindo-Ihe formas físicas nunca experimentadas antes. 
A este leque enorme de possibilidades plásticas acrescenta-se uma outra grande mudança: a que tem vindo a ocorrer devido ao surgimento de novas atividades perceptivas que nunca existiram antes nas diversas formas de abordagem humana ao fenômeno artístico. Em regra, esta aproximação era quase sempre de natureza visual e relativamente distanciada.

O espectador é externo à obra e nem sequer é considerado quando da sua concepção. Em muitos movimentos do pós-guerra, o espectador passa a ser agora uma unidade considerada logo à partida na concepção da obra de arte e esta, por vezes, nem sequer adquire forma física palpável ficando apenas no plano conceitual. Logo, a necessitar de uma abordagem que, mais do que perceptível, deverá ser inteligível.

Por fim, as novas técnicas artísticas, em todos os âmbitos expressivos, que vão do teatro (teatro do absurdo, acontecimento, etc.) à música (música minimal repetitiva, música aleatória, etc.) passando pelas artes plásticas vão marcar intensamente todo o panorama atual das artes em geral.

No campo que nos interessa - o das artes visuais - e a sua relação com a ilustração infantil, parece-nos claramente marcante a influência que muitas técnicas como o "dripping", a "assemblage", a "collage", e as diversas técnicas mistas ("mixed media" no original em inglês) vão ter na concepção da ilustração de livros infantis.

Estas técnicas foram quase todas inventadas no século $X X$ e, de alguma forma, constituem-se como o corolário não só de um saber prático dos artistas que ousaram sair do trinômio pincel/tinta/superfície (tela ou papel) que vinha marcando a praxis artística desde tempos imemoriais, como também de uma necessidade de expansão, por via técnica/material, das possibilidades expressivas capazes de responder melhor aos desafios colocados por um cotidiano qualitativamente muito diferente do que foi vivido num passado recente.

Foram, sem dúvida, uma resposta daquilo que podemos chamar de "investigação" artística, aquela que muitos artistas realizam fora dos parâmetros e dos esquemas investigativos tradicionalmente considerados pelo mundo acadêmico.

A "investigação" artística é pois o que leva ao aparecimento de novas técnicas e formas de expressão e estas procuram responder expressiva e emocionalmente a novos conceitos e a novas necessidades geradas pelas novas "tensões vitais" a que antes nos referimos e que necessariamente diferem em cada momento histórico. 
Aquilo que consideramos investigação artística não é realizada a partir de perguntas de investigação ou a partir de instrumentos de recolha de dados para posterior interpretação a partir de um determinado enquadramento teórico, que é a via tradicional de qualquer estrutura investigativa no campo das ciências humanas. Em investigação artística os produtos da investigação são as obras de arte que, por sua vez, são os próprios dados, o que torna numa espécie de aporia qualquer tentativa de aproximar modos e propósitos de investigação tão díspares.

Quadro 2: Mudanças artísticas fundamentais no século XX

\begin{tabular}{|c|c|c|}
\hline $\begin{array}{c}\text { Novos materiais e novos } \\
\text { objetos de arte }\end{array}$ & $\begin{array}{l}\text { Novas atividades } \\
\text { perceptivas }\end{array}$ & $\begin{array}{l}\text { Novas formas e novas } \\
\text { técnicas artísticas }\end{array}$ \\
\hline $\begin{array}{l}\text { - Modelo científico; leis e } \\
\text { conceitos científicos. } \\
\text { - Máquinas. } \\
\text { - Materiais tecnológicos, } \\
\text { produtos de máquinas. } \\
\text { - Objetos standardizados, } \\
\text { padrões repetidos. } \\
\text { - Mecanismos eletrônicos e } \\
\text { instrumentos. } \\
\text { - Materiais simples. } \\
\text { - Objetos de uso cotidiano }\end{array}$ & $\begin{array}{l}\text { - Tipos alargados de } \\
\text { percepção. } \\
\text { - Crescente integração de } \\
\text { objetos. } \\
\text { - Inclusão de outros } \\
\text { receptores sensitivos } \\
\text { (tátil, cinestésico, etc.) } \\
\text { - Rejeição das "proibições" } \\
\text { estéticas (ex. o erótico). } \\
\text { - Eliminação da distinção } \\
\text { entre: } \\
\text { - objeto e observador; } \\
\text { - espectador, criador e } \\
\text { objeto; } \\
\text { - criador e observador; } \\
\text { - "performer", artista e } \\
\text { observador. } \\
\text { - Integração da arte com a } \\
\text { vida cotidiana: } \\
\text { - oportunidade; } \\
\text { - acontecimentos } \\
\text { prosaicos; } \\
\text { - objetos comuns; } \\
\text { - Destronização da arte, } \\
\text { inclusão do: } \\
\text { - primitivo; } \\
\text { - grotesco, } \\
\text { - "brutalismo" } \\
\text { - Funcionalismo, a arte } \\
\text { como habilidade, } \\
\text { tecnologia. } \\
\text { - Comentário social. }\end{array}$ & $\begin{array}{l}\text { - "Teatro da crueldade". } \\
\text { - "Teatro do absurdo". } \\
\text { - Acontecimento } \\
\text { (Happening). } \\
\text { - Fotografia. } \\
\text { - Cinema. } \\
\text { - Ambientes. } \\
\text { - Arquitetura } \\
\text { funcional. } \\
\text { - Escultura cinética. } \\
\text { - Object trouvée } \\
\text { - Assemblages } \\
\text { - Dripping } \\
\text { - Música aleatória. } \\
\text { - Música repetitiva. } \\
\text { - Música eletrônica. } \\
\text { Etc... }\end{array}$ \\
\hline
\end{tabular}

Adaptado de BERLEANT, A. "Aesthetics of the Contemporary Arts"'" In ALPERSON P. (Ed.) The Philosophy of the Visual Arts. Oxford: Oxford Universitary Press, 1992. PP. 422-423. 


\section{Pontos de contato entre uma arte contemporânea enfocada nas pessoas e a ilustração Infantil}

Como dissemos anteriormente, os novos objetos artísticos têm se expandido crescentemente até formas e conceitos nunca antes experimentados, aproveitando não só as novas técnicas materiais (assemblage, collage, dripping, mixed media, etc.) mas também as novas capacidades expressivas proporcionadas pelas novas tecnologias ${ }^{4} \mathrm{da}$ eletrônica e da informática, que tiveram o seu nascimento no século XX mas que continuam, já no nosso século, a experimentarem um crescimento exponencial sem precedentes e que as tornaram fundamentais para alguns sistemas de circulação da obra de arte $^{5}$. Este fenômeno que não afeta só as artes visuais. Segundo Berleant (1992, p. 420):

Somos confrontados com sons cujas formas de frequência e timbres sofreram uma enorme expansão com o uso de sintetizadores. Somos encadeados por luzes, cortados por espelhos, inflamados pela dança, transportados por filmes para fascinadas absorções. Andamos dentro de esculturas, reajustamos o nosso sentido de ordem espacial em ambientes criados, partilhando estruturas arquitetônicas dispondo dos 'performers' como num espetáculo teatral ou de dança. Somos feitos para ver o sacrilégio, o obsceno, o mundano, o comercial, para ouvir o som do trânsito ou o gotejar da água(...) As artes contemporâneas, não apenas expandiram enormemente o tipo tradicional de objetos e de sentidos estéticos, como também assentam agora em capacidades sensitivas jamais experimentadas anteriormente, (ou pelo menos reconhecidas). Certamente o apelo ao tátil e ao cinestésico representa a característica na expansão dos limites da percepção estética.

É esta diversidade de propostas artísticas e são os variados "convites" à sua experimentação estética que tornam a arte contemporânea extraordinariamente eclética no panorama cultural ocidental. O "alargamento" da sensibilidade estética produziu pelo menos duas mudanças principais na experiência perceptiva das artes contemporâneas (BERLEANT, 1992, p.421).

Em primeiro lugar, há agora uma eliminação deliberada de qualquer separação perceptiva entre os principais fatores da experiência estética. O objeto de arte, por

\footnotetext{
${ }^{4}$ Já antes, na primeira metade do século $X X$, alguns autores, como Benjamin, (a que nos referiremos mais à frente) tinham refletido sobre a fotografia e o cinema e a influência que irão ter sobre o fenômeno artístico e sobre a noção de obra de arte. Em 1936, ano do famoso ensaio e Benjamin "A obra de arte na era da sua reprodutibilidade mecânica" eram a fotografia e o cinema que constituíam as formas de arte fundadas nas tecnologias que naquela altura caminhavam ainda em direç̧ão à maturidade e à relevância que irão conhecer um grande incremento, sobretudo a partir da IIa Guerra Mundial (e até durante esta, como o pernicioso exemplo do aproveitamento político das novidades do meio tecnológico e artístico, basta recordar os famosos documentários de Leni Rifensthal para Adolf Hitler).

${ }^{5}$ Referimo-nos às cada vez mais populares Web Galerias e Web Zines digitais que difundem as artes visuais à escala do planeta, em tempo real e a custos reduzidíssimos. Os portfolios digitais são hoje um formato quase obrigatório para os artistas que se querem dar a conhecer em todo o planeta.
} 
exemplo, impôs a si próprio a participação num conjunto de estratégias que tornam inevitável o seu efeito sobre o público, quebrando a sua passividade contemplativa tradicional. Este efeito ocorre por intermédio do uso de estratagemas absolutamente novos, que são utilizados em muitas formas de expressão artística que cobrem um campo variado da atividade artística ${ }^{6}$. Muitas formas de expressão introduzem um fator dramático com a participação do observador na obra, da mesma forma que em muitas técnicas o artista e o objeto fundem-se e integram-se para a obtenção de um dado efeito sobre a assistência ("Happenings"), não sendo raro a participação desta no efeito final da proposta artística.

Uma segunda mudança ocorrida na experiência perceptiva consiste na integração deliberada na arte de características simples da vida cotidiana (que os Quadros 2 e 3 sintetizam). A relação entre a vida e a arte sempre alimentou, por exemplo, o gênero literário da novela, mas foi a partir do impressionismo durante o último quartel do século XIX, que o cotidiano passou, crescentemente, a tomar uma posição central na temática artística em artes visuais.

Todavia, o modernismo e muitas correntes artísticas do século $\mathrm{XX}$, na ânsia de levar até limite as formas e os conceitos de arte voltaram a esquecer a vida cotidiana e só o pósmodernismo das duas últimas décadas do século XX (tendo, em certa medida, como precursora a Arte Pop dos anos 60) voltou a incluir a vida social ${ }^{7}$ como um tema persistente das suas variadas formas de manifestação artística.

Levado ao limite, esta participação do público na obra, pode fazer, por exemplo, que o leitor ou o espectador seja agora chamado a escolher o fim que mais deseja para a novela ou filme televisivo. Os mais prosaicos acontecimentos e os simples objetos comuns da vida cotidiana são integrados e refuncionalizados como objetos artísticos. Este convite à participação cívica das pessoas na dinâmica artística, quer como simples apreciadores, quer ainda, como co-autores deliberados, em experiências mais ricas e mais ousadas, contribuiu em definitivo para a destronização da arte como fenômeno

\footnotetext{
${ }^{6}$ Na música e no teatro pede-se a colaboração pro-ativa da audiência, por vezes os músicos e os atores encontram-se no meio da assistência interagindo com ela. $\mathrm{Na}$ artes visuais pode-se participar nas obras, caminhando dentro de esculturas ou vendo a nossa imagem refletida num espelho estrategicamente dissimulado num dado "ambiente" criado ("Instalação").

7 O que leva Jencks (na sua obra "What is Postmodernism" publicado em 1989 em Londres: Academy Editions, p.7) a definir a pós-modernidade como uma era em que nenhuma ortodoxia pode adotar-se sem autoconsciência e ironia dado que todas as tradições parecem reter alguma validade. Jencks considerava que isto era devido em parte à chamada explosão informativa, à chegada do saber organizado à globalização das comunicações e à cibernética.
} 
excelso, contribuindo igualmente para a sua reintegração no curso normal das atividades humanas. Daí que faça todo o sentido a sua inclusão no currículo escolar.

Em todo o caso, esta consolidação do fenômeno artístico, posicionando-se no coração do tecido social contemporâneo não foi feita sem lutas e sem antagonismos e necessariamente implicou uma mudança radical na apreciação estética que procuramos sintetizar no quadro seguinte.

Quadro 3 - Características da nova estética

\begin{tabular}{|c|c|c|}
\hline $\begin{array}{l}\text { O conceito básico: } \\
\text { O campo estético }\end{array}$ & $\begin{array}{c}\text { As características } \\
\text { negativas }\end{array}$ & $\begin{array}{c}\text { As características } \\
\text { positivas }\end{array}$ \\
\hline $\begin{array}{l}\text { 1. Uma "Teoria geral da } \\
\text { Estética" mais inclusiva. } \\
\text { 2. Integração entre: } \\
\text { a. artista. } \\
\text { b. objeto. } \\
\text { c. observador. } \\
\text { d. "performer". } \\
\text { 3. Relação funcional entre: } \\
\text { a. criador- } \\
\text { observador-performer. } \\
\text { b. trabalho e objeto } \\
\text { c. a experiência estética } \\
\text { como atividade } \\
\text { funcional. } \\
\text { Inclusão de: } \\
\text { a. materiais. } \\
\text { b. acontecimentos. } \\
\text { Difusão de: } \\
\text { a. crescente continuidade } \\
\text { entre o estético e o "não- } \\
\text { estético". } \\
\text { b. conexão próxima da } \\
\text { arte com a sociedade, } \\
\text { como comentário, sátira e } \\
\text { crítica. }\end{array}$ & $\begin{array}{l}\text { 1. Recusa da importância } \\
\text { a unidade, harmonia. O } \\
\text { que contribui para o } \\
\text { isolamento do objeto } \\
\text { artístico. } \\
\text { 2. Rejeição do ideal (ex. a } \\
\text { beleza) como o fim da } \\
\text { arte. } \\
\text { 3. Recusa da atitude } \\
\text { distanciada e } \\
\text { contemplativa. } \\
\text { 4. Recusa da atitude } \\
\text { "desinteressada": } \\
\text { a. Recusa da } \\
\text { separação entre } \\
\text { objeto de arte e a } \\
\text { vida. } \\
\text { b. Recusa do carácter } \\
\text { único da arte e } \\
\text { dos acordos } \\
\text { institucionais que } \\
\text { a perpetuam (Ex: } \\
\text { museus etc.) }\end{array}$ & $\begin{array}{l}\text { 1. Continuidade } \\
\text { entre a vida e } \\
\text { a arte. } \\
\text { a. processo, } \\
\text { movimento. } \\
\text { b. funcionalismo } \\
\text { 2. Integração } \\
\text { perceptiva dos } \\
\text { elementos da } \\
\text { situação } \\
\text { estética. } \\
\text { 3. Criação } \\
\text { artística como } \\
\text { iniciativa } \\
\text { cooperativa. }\end{array}$ \\
\hline
\end{tabular}

Adaptado de BERLEANT, A. Aesthetics of the Contemporary Arts" In ALPERSON P. (Ed.) The Philosophy of the Visual Arts. Oxford: Oxford Universitary Press, 1992. pp. 423.

Esta arte feita com materiais simples e comuns (tecidos, botões, caixas, cartão, cartolinas, papel de jornal, folhas de árvore, cordéis, embalagens, etc.) muitos deles recuperados do lixo (procurar e ver exemplos da técnica da assemblage na obra de 
Robert Raushenberg) é a que vai também influenciar muitos ilustradores de livros infantis, muitos deles com formações superiores artísticas onde tiveram contato com a obra dos artistas contemporâneos que diversificaram e expandiram o uso de técnicas de expressão plástica não convencionais.

No entanto não é só no plano técnico-expressivo que os contatos entre aspectos significativos da arte contemporânea e a ilustração de livros infantis se podem estabelecer. Ao nível dos aspectos formais e da estilização das figuras, das personagens, dos fundos e dos cenários, também se pode verificar uma espécie de cumplicidade entre a forma na arte contemporânea e a forma na ilustração infantil.

Por outro lado muitos dos movimentos estéticos que identificamos no quadro 1 buscam uma espontaneidade e uma espécie de ingenuidade muito próxima do fazer infantil. Outros, muito recentes, como o movimento Immagine \& Poesia, fundado por italianos e norte americanos em $2007^{8}$ procuram relacionar e integrar texto e imagem artística. É, muito provavelmente, o movimento contemporâneo que atualmente o faz com toda a intencionalidade, como fica bem expresso no seu manifesto ${ }^{9}$ em dez princípios, que transcrevemos a seguir.

Quadro 4: Manifesto do Movimento Immagine \& Poesia

\begin{tabular}{|l|l|}
\hline 1 & $\begin{array}{l}\text { Cultura através da poesia e arte deve ser o alimento do espírito das novas } \\
\text { gerações. }\end{array}$ \\
\hline 2 & Poesia e arte figurativa levam a momentos de fertilização de uma para outra. \\
\hline 3 & $\begin{array}{l}\text { Cada forma de expressão pode inspirar outras: o nosso objetivo é sua } \\
\text { integração. }\end{array}$ \\
\hline 4 & $\begin{array}{l}\text { Da integração da poesia e arte figurativa, reciprocamente encorajadas, uma } \\
\text { nova forma rica e completa de arte pode se originar. }\end{array}$ \\
\hline 5 & $\begin{array}{l}\text { O movimento está aberto a artistas e escritores vindos de diferentes } \\
\text { localizações geográficas e bases culturais. }\end{array}$ \\
\hline 6 & $\begin{array}{l}\text { A Inter-ação desses artistas e escritores pode aumentar o entendimento e } \\
\text { respeito dos outros. }\end{array}$ \\
\hline 7 & $\begin{array}{l}\text { Somos a favor da colaboração que pode acontecer via mídia tradicional ou via } \\
\text { Internet. }\end{array}$ \\
\hline 8 & As novas tecnologias serão preferidas na troca de ideias criativas. \\
\hline
\end{tabular}

\footnotetext{
${ }^{8}$ Immagine \& Poesia é um movimento artístico e literário internacional fundado em 2007 na Itália, na cidade de Turim, no Teatro Alfa, tendo sido patrocinado pela poeta e escritora Aeronwy Thomas. Para além da fundadora, os outros membros fundadores foram Gianpiero Actis, pintor; Silvana Gatti, pintora; Sandrina Piras, poeta e Lidia Chiarelli, coordenadora e ideóloga do movimento. O poeta americano Lawrence Ferlinghetti tornou-se um membro do Comité Honorário do movimento em 2009.

9 Manifesto do movimento Immagine \& poesia foi traduzida para português pela brasileira Cristiane campos (ver em http://imagespoetry.wordpress.com/the-manifesto-portuguese-translation-by-cristiane-camposbrazil/).
} 
9 Queremos lutar contra a apatia, a banalidade, a superficialidade e dar apoio à atividade, imaginação, originalidade e pesquisa.

10 O movimento de Imagens \& Poesia está aberto para mais desenvolvimentos e ligações com outras disciplinas e formas de arte.

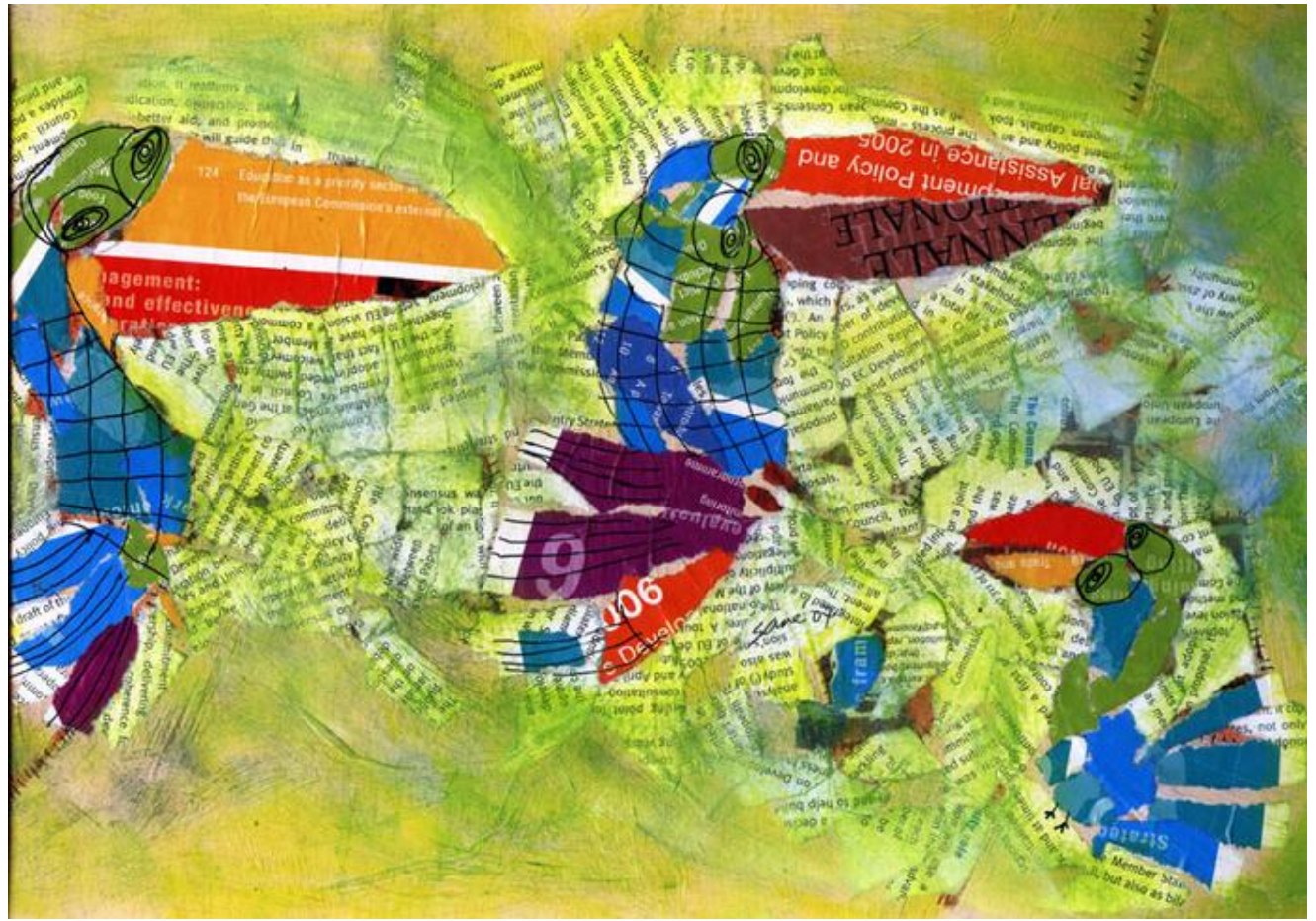

Figura 1: Obra de Eria Nsubuga (Uganda), Título: "A personalidade dos pássaros". 2011, Colagens e técnica mista, Aprox. 38 x $42 \mathrm{~cm}$. (download de http://www.artbreak.com/eria, reproduzido com autorização da artista)

Poema: Lawrence Ferlinghettti

...And there were birds of every color black birds \& yellow birds $\&$ red birds from the lands of every liberation movements...

A abertura a artistas, a expressões artísticas e a culturas situadas fora do âmbito geográfico ocidental, que tradicionalmente tem monopolizado o discurso gerado à volta do fenômeno artístico, é um dos aspectos educativa e socialmente mais interessantes do movimento Immagine \& Poesia. O trabalho de Nsubuga (figura 1) parece-nos ilustrar na perfeição a nossa tese, segundo a qual, a distância que vai da ilustração infantil contemporânea a determinadas formas de arte contemporânea é, de fato, muito tênue, quase imperceptível, dando força a uma opinião de Carol Hurst (1997, p.2) segundo a qual o livro ilustrado é normalmente considerado a primeira introdução da criança à arte e que não podemos esperar que essa aproximação da criança a um fenômeno tão vibrante quanto excitante, seja facilitada por intermédio de livros medíocres ou de concepção pobre. 


\section{O que vale o livro ilustrado e o que queremos que a criança aprenda com ele}

Segundo Gleeson, (2003, p.2) um livro ilustrado é uma história contada em palavras e imagens. Quer a imagem, quer a palavra, constituem um contributo importante para a forma como a história é contada e para a forma como o significado é criado.

Uma "ilustração" de qualidade, com todo o seu potencial, não é o mesmo que uma "história decorada". Nesta última, as palavras, por si só, podem contar a história tendo as imagens um papel de quebrar o ritmo do texto ou de apenas decorá-lo. Num livro ilustrado de qualidade as ilustrações não são meras decorações e são tão necessárias quanto cruciais. Aclaram na mente da criança certos aspectos da história que a limitação e a rigidez do textual não permite. $O$ truque que utilizam muitos escritores para crianças é precisamente o de poetizarem o texto, tornando-o lírico, aumentando-Ihe a capacidade de gerar significados e "visões" que abordagens mais formalistas textuais impedem. De certa forma aproximam assim o texto da ilustração, se esta for concebida com os mesmos propósitos estéticos, dando assim resposta aos princípios 2, 3 e 4 do manifesto Immagine \& Poesia anterior.

No entanto, foi a publicação de um livro de Bruno Bettelheim, um psicólogo austríaco, naturalizado norte-americano, nos finais dos anos 70, que veio a alterar a forma como o mundo acadêmico passou a olhar para a literatura infantil. A obra denominou-se, ousadamente, "Uses of Enchantment: The meaning and importance of fairy tales. "10

A partir de uma perspectiva psicanalítica a obra é baseada em duas premissas principais (RICHMAN, 1977, p.141). A primeira sustenta que o tradicional conto de fadas representa uma luta básica contra as dificuldades extremas que serão vencidas se, firmemente, o indivíduo se conhecer e se ajustar, ultrapassando assim todos esses obstáculos. Este conceito que envolve uma certa ideia de superação é apresentado continuamente nos contos de fadas como uma parte intrínseca da existência humana. $A$ segunda premissa é a que sustenta que a necessidade da criança pelo mágico habilita-a a conceptualizar, por via dos contos de fadas, a emergência do "bem" sobre o "mal", como algo que acabará por fruir e confia no que o conto diz porque normalmente o que se comunica do conto é consistente com o seu próprio mundo. Richman (1977, p.141) destaca em Bettelheim a importância da externalização por parte da criança. Nesse sentido, o conto de fadas permite uma clareza incomum na fantasia, porque as

\footnotetext{
${ }^{10} \mathrm{O}$ livro de Bettelheim teve, num espaço de tempo relativamente curto, uma tradução portuguesa no Brasil. O Original foi publicado em 1977 sob o título "The Uses of Enchamtmen: The Meaning and Importance of Fairy Tales, pela Editora Knopf de Nova Iorque, no Brasil foi publicado logo em 1979 pela Editora Paz e Terra do Rio, com o título "Psicanálise dos contos de fadas", obra a que recorremos para a escrita deste texto.
} 
tradicionais formas de inicio dos contos como o "há muito, muito tempo atrás", ou o "era uma vez", permitem a construção preliminar de um terreno seguro e neutro para a externalização. Como o conto de fadas é apresentado recorrendo, em regra, à linguagem dos símbolos, a criança não pode externalizar, com base em fatos concretos, mas através do simbólico.

A chave do papel e do impacto das ilustrações contemporâneas sobre a infância encontra-se assim justificado. Daí o fato das ilustrações de qualidade evitarem (com consciência, ou sem ela, por parte dos ilustradores) enfoques miméticos sobre a realidade e reproduções fotográficas e demasiado realistas.

A opção recorrente por parte dos ilustradores por técnicas mistas e estilizações formais ousadas, incrementam e facilitam uma abordagem aos significados e às emoções proporcionadas pela fruição de uma imagem por via do jogo simbólico que só se aclara, na mente da criança, pela segurança e condução paralela para um propósito desejado, que é proporcionada pelo texto. O texto tem assim uma função estruturante. Sendo uma obra literária um objeto "construído" com uma certa estrutura, acaba por nos propor um modelo de coerência gerado por uma espécie de poder e de força da palavra organizada. E quando falamos de "palavra organizada", nem sequer nos referimos às questões gramaticais e ortográficas, mas sim à ideia que pode muito facilmente ser atribuída às palavras uma dada intencionalidade, que pode ser moral, religiosa, política, poética etc.

Segundo Cândido, (2004, p. 177) "A organização da palavra comunica-se ao nosso espírito e o leva, primeiro, a se organizar; em seguida, a organizar o mundo". Joseph Schwarcz $(1982,1991)$ sustenta igualmente que as ilustrações têm um marcado efeito psicológico sobre as crianças e que as ilustrações que estas encontram na literatura ensina-as a lidarem com problemas nas suas vidas, como modelá-las e como se tornar adultos. Embora Schwarcz sustente os seus argumentos em termos de desenvolvimento psicológico, assume no entanto alguns princípios da chamada alfabetização visual, um termo que Richard Sinatra (1986, p.57) define como "a reconstrução ativa da experiência visual passada com as informações recebidas para a obtenção de significado". Na realidade, a alfabetização visual tem como um dos seus conceitos chave a ideia de "schematta", que Piaget define como "imagens mentais" ou "padrões de ação" que se tornam uma forma de representação e organização de todas as experiências sensóriomotoras prévias da criança" (Sinatra, 1986, p.9). As ilustrações que as crianças visualizam no seu contacto inicial com o livro ilustrado, como a experiência sensorial, podem tornar-se partes importantes deste esquemas, assumindo-se como uma espécie de blocos de construção do seu pensamento, algo a que eles passam a referir-se nas 
suas ações à medida que crescem, cumprindo o papel que Schwarcz Ihes atribui na formação da sua identidade.

Joseph Schwarcz (1991) observa que, durante toda a infância, a personalidade do indivíduo vai crescendo e se vai expandindo. Paulatinamente um conjunto de processos biopsicológicos, a própria herança genética, a constituição física e as experiências de vida irão levar a criança em direção a um maior grau de consciência do seu próprio ego e da sua autonomia. Efetivamente, a busca pela sua individualidade inclui muitos aspectos que se inter-relacionam. Os livros ilustrados atuais podem e devem ser considerados mais do que tentativas para simplesmente entreter a criança. Acabam, muitos deles, por serem fundamentais para a construção da sua personalidade, pela forma como vão influenciar a sua mente quando da sua dupla recepção (texto-imagem), quer seja lido pelo professor, pelos pais ou autonomamente.

Portanto, a preparação e a construção de um futuro leitor passará pela promoção e pelo contato precoce com a literatura. O livro ilustrado é assim incontornável nos estudos e na investigação acadêmica por dois motivos: pelo valor das experiências precoces na construção da subjetividade e pela potência da literatura em criar e recriar o mundo e a identidade infanto-juvenil.
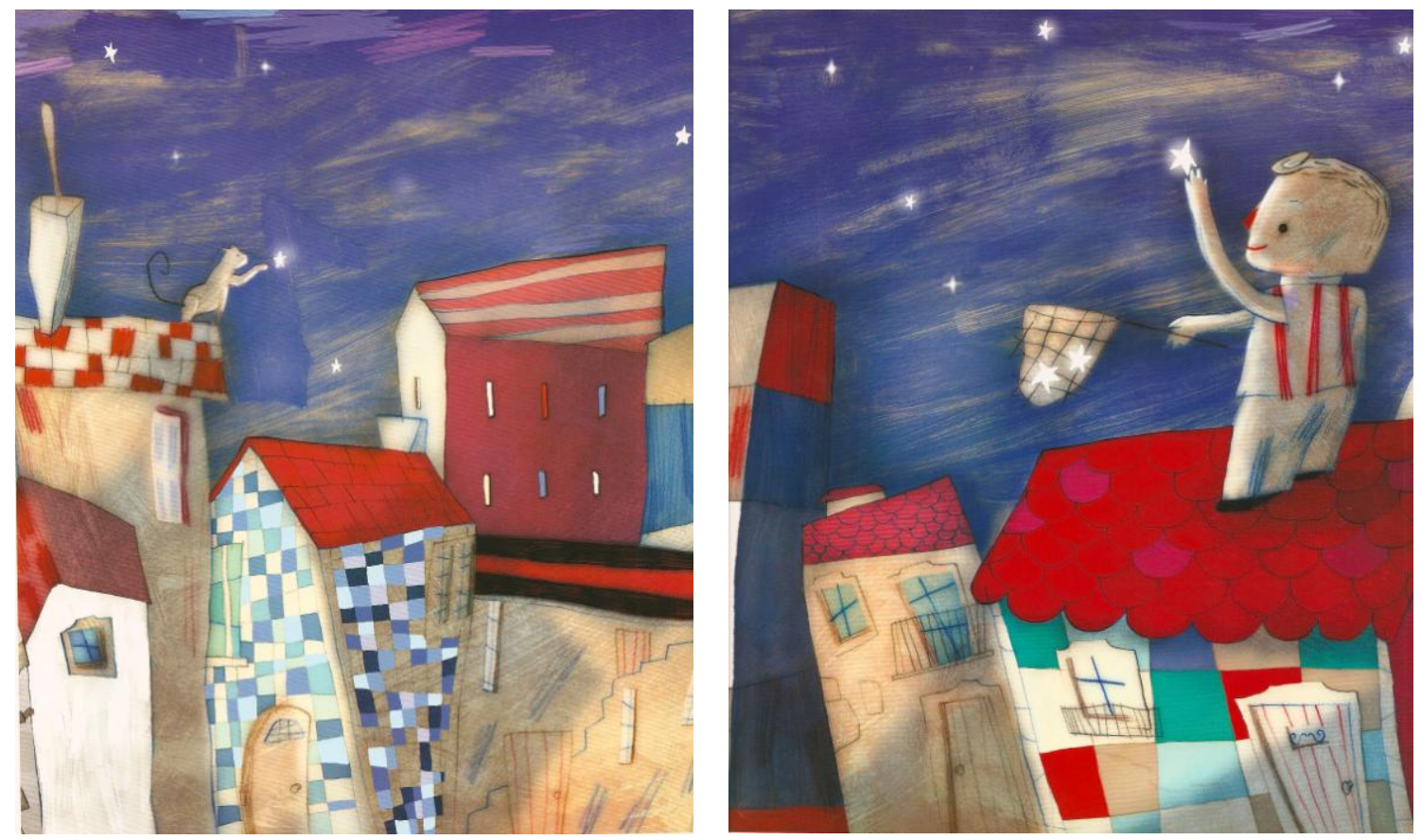

Figura 2: Ilustração do ilustrador português José Manuel Saraiva, publicada no livro "Rouge Cerise" (Cereja Vermelha) ${ }^{11}$, técnica mista. Reproduzido com autorização do artista

${ }^{11}$ Rouge Cerise de François David e José Saraiva; Broché: 27 páginas; Editor: Edition Sarbacane (30 Maio 2006); Colecção: Girafon Poche; Língua: Français; ISBN-10: 2848651121; ISBN-13: 978-2848651125. 
Conforme destaca Rosamilha (1982), do ponto de vista psicológico, existe uma Literatura Infantil com características próprias, que leva em conta o modo particular como a criança vê o mundo e se relaciona com ele. A ilustração, como a de José Saraiva, (ver Figura 2), que atende a estes pressupostos considera-se de boa qualidade. É um dos exemplos desta migração operada por muitos artistas, que "viajam" das artes visuais contemporâneas para a ilustração infantil, tendo as técnicas de expressão como elo de ligação.

Uma criança entende e concebe uma estrela não como uma entidade do cosmos, cheia de energia, mas sim na sua escala micro, como algo que se pode personificar ou dominar e, consequentemente, que uma criança de um determinado nível etário pode apanhar e colher numa qualquer noite de luar.

Mas uma delicada relação entre poder e literatura pode também ser sublinhada a partir de diversos autores sob clara influência da escola critica francesa e de nomes como, Jean-François Lyotard, Jacques Derrida e Michel Foucault. Já nos inícios do anos 80, Sandroni (1980, p.12) precedendo até alguns textos que viriam a ser marcantes na teoria critica francesa, afirma ser inerente ao ato criador o rompimento de hábitos. $\mathrm{Na}$ realidade já alguém afirmou que o pior inimigo da criatividade é a rotina. A ideia fundamental é que não se siga a norma a ser seguida. Segundo Sandroni (1980, p.12) "Toda obra literária contém elementos de transgressão. A hipótese levantada é a de que a Literatura só existe quando instaura a angústia, a reflexão crítica, quando busca uma área de atrito com o leitor." Isto significa que o educador e o autor/ilustrador se quiserem na realidade desenvolver obras com impacto sobre os seus leitores/visualizadores, deverão sair de uma confortável e inócua posição de neutralidade, que uma determinada posição social conservadora aconselha, e assumir uma postura mais interventiva.

Esta posição de neutralidade está muito próxima e concorre a favor da manutenção um certo "equilíbrio". Consequentemente, a literatura e toda a "verdadeira" arte, onde ousamos incluir a ilustração infantil, é uma ameaça, no sentido em que pretende romper e subverter esse equilíbrio que busca explicar os fenómenos naturais e sociais como algo que "sempre assim foi" ou em relação quais "não mais nada a fazer" Senão aceitar uma presumível ordem natural das coisas.

Recuando uma década, Higgins (1971, p.1), procura sublinhar a importância da escrita para crianças, reconhecendo mesmo como Literatura aqueles livros que solicitam da criança a manifestação de um conjunto de sentimentos que de fato, nos tornam 
humanos, tais como: " ... zangar e entristecer, rir e chorar, lembrar e projetar, sentir a maciez e algumas vezes a dureza dos elementos, julgar e mostrar compaixão, imaginar e maravilhar-se...".

$\mathrm{Na}$ realidade estes sentimentos e estas atitudes levam em consideração os aspectos internos da criança, da mesma forma que uma boa parte da literatura adulta de qualidade considera, e procura inter-agir, com a subjetividade dos seus leitores. Daí que nos já longínquos anos 70, Higgins tenha considerado que a Literatura Infantil não podia ser divorciada da Literatura como um todo, sendo por isso mesmo uma manifestação muito séria de cultura.

\section{Conclusões}

As formas de leitura de livros ilustrados, primeiro "ouvida e vista" (no pré-escolar), depois "acompanhada e partilhada" e, finalmente, "autônoma e fruída", integra-se na valorização das experiências precoces para a constituição subjetiva do indivíduo. A literatura pode ser pois considerada como um dos processos de humanização mais sérios que existe.

Howard Gardner destaca e defende um conjunto de ideias e princípios que, na realidade, deveriam servir de guiões tanto para qualquer educador infantil, como para qualquer escritor/ilustrador de livros para crianças:

Eu quero que as minhas crianças compreendam o mundo, mas não apenas porque o mundo é um lugar fascinante e a mente humana é curiosa. Quero que o compreendam de modo a se posicionarem para fazer dele um lugar melhor. O conhecimento não é o mesmo do que moralidade, mas precisamos de o compreender se queremos evitar erros do passado e seguirmos direções mais produtivas. Uma parte importante dessa compreensão é a de saber quem somos e o que podemos fazer...Finalmente, devemos sintetizar as nossas compreensões sobre nós mesmos. A performance para compreender o que importa é a que podemos levar a cabo como seres humanos num mundo imperfeito que podemos afetar, para o bem e para o mal (GARDNER, 1999, p.180-181).

A ilustração de livros infantis é, simultaneamente, e de forma crescente, uma forma artística por direito próprio e uma parte integral da composição literária do livro que cada vez mais tem vindo a ser considerado como obra de arte. Para apreciar completamente os estilos, os meios de expressão e as técnicas representadas devemos duplamente familiarizar-nos não só com aspectos conceituais, didáticos e técnicos da arte 
contemporânea, como também com os propósitos, as finalidades, a composição e a arquitetura de livros para crianças.

Assim como muitos dos movimentos da arte contemporânea, que destacamos, o livro ilustrado constitui um vetor, para que a "educação para a compreensão" de Gardner se imponha, num mundo cada vez mais marcado por fenômenos e pressões alineantes que tendem a entorpecer o indivíduo e as suas opções de escolha.

A revitalização da educação bem como a crença que podemos ter nela - como forma cultural de humanização do indivíduo - dependerá muito das formas como os autores (escritores/ilustradores, artistas e educadores) conseguirem gizar respostas vibrantes e criativas aos inúmeros problemas que se têm agudizado nestes últimos anos e que requerem respostas urgentes e contundentes.

\section{Referências}

ALPERSON, P. (Ed.). The Philosophy of the Visual Arts. Oxford: Oxford University Press, 1992.

BERLEANT, A. Aesthetics of the Contemporary Arts In Alperson M (Ed.) The Philosophy of the Visual Arts, (pp. 415-425). Oxford: Oxford University Press, 1992.

BETTELHEIM, B. A psicanálise dos contos de fadas. Rio de Janeiro: Paz e Terra, 1979.

BUCKINGHAM, D. Moving Images: Understanding children's emotional responses to television. Manchester: Manchester University Press, 1996.

After the Death of Childhood: Growing up in the age of electronic media. Cambridge: Policy Press, 2000.

(Ed.) Small Screens: Television for Children. Leicester: Leicester University Press, 2002.

CÂNDIDO, A. O direito à literatura In: Vários Escritos. São Paulo: Duas Cidades/Ouro sobre Azul, 2004. p. 169-91.

FRASCINA, F; HARRISON, C. (Eds). Modern Art and Modernism: A critical anthology. Londres: Harper \& Row, 1982. 
GARDNER, H. Intelligence Reframed. Multiple Intelligences for the 21st Century, New York: Basic Books, 1999.

Frames of Mind: The theory of multiple intelligences. New York: Basic Books, 1983.

GLEESON, L. Making Picture Books. Lindfield: Scholastic, 2003.

HIGGINS, J. E. Beyond words. Nova York: Teachers College Press, 1971.

HURST, C. Children's Literature Newsletter. Vol. 2, No 1. January, 1997.

RICHMAN, H. The Uses of Enchantment, Bruno Bettelheim. Book Review, Modern Psychoanalysis, 2, 1977, p.141

ROETHLER, J. Reading in Color: Children's Book Illustrations and Identity Formation for Black Children in the United States, African American Review, Vol. 32. No1, 1998. pp.95-105.

ROSAMILHA, N. Et alt. Literatura infantil e ansiedade. Tecnologia Educacional, 10(44), 1982. pp.31-36.

SANDRONI, L. C. A estrutura do poder em Lygia Bojinga Nunes. In: Revista Tempo Brasileiro, 63, 1980, p.11-25.

SCHWARCZ, J. The Picture Book Comes of Age: Looking at Childhood Through the Art of Illustration. Chicago: American Library Association, 1991.

Ways of the Illustrator: Visual Communication in Children's Literature.

Chicago: American Library Association, 1982.

SINATRA, R. Visual Literacy Connections to Thinking, Reading and Writing. Springfield: Thomas, 1986. 